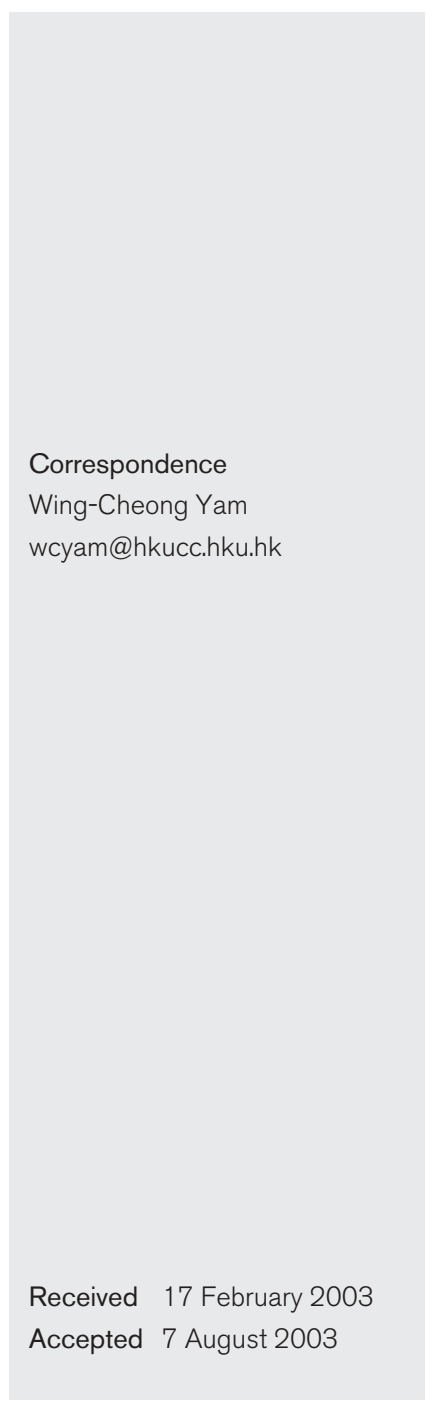

\title{
Detection of katG Ser315Thr substitution in respiratory specimens from patients with isoniazid-resistant Mycobacterium tuberculosis using PCR-RFLP
}

\author{
Eric Tung-Yiu Leung, ${ }_{1}^{1}$ Kai-Man Kam, ${ }^{2}$ Agatha Chiu, ${ }^{2}$ Pak-Leung Ho, ${ }^{1,3}$ \\ Wing-Hong Seto, ${ }^{1}$ Kwok-Yung Yuen ${ }^{1,4}$ and Wing-Cheong Yam ${ }^{1}$ \\ ${ }^{1}$ Department of Microbiology, The University of Hong Kong, University Pathology Building, Queen \\ Mary Hospital, Pokfulam Road, Hong Kong SAR, China \\ ${ }^{2}$ Tuberculosis Reference Laboratory and Public Health Laboratory, Department of Health, Hong \\ Kong SAR, China \\ ${ }^{3,4}$ Centre of Infection ${ }^{3}$ and HKU-Pasteur Research Centre ${ }^{4}$, Faculty of Medicine, The University of \\ Hong Kong, Hong Kong SAR, China
}

\begin{abstract}
Mutations in the katG locus of catalase peroxidase in Mycobacterium tuberculosis (MTB) account for major isoniazid (INH) resistance. In the South China region, a collection of 906 respiratory specimens and 142 MTB isolates was used to evaluate the sensitivity and specificity of a PCR-RFLP method for the detection of INH resistance-associated mutations. Except for four catalase-negative MTB isolates, katG PCR for a 620-bp amplicon was successful for all purified MTB isolates. For respiratory specimens, diagnostic sensitivity and specificity of katG PCR was 85 and $100 \%$. Subsequent RFLP of the katG amplicons by Mspl digestion identified that $51 \%$ of INH-resistant MTB were associated with the Thr315 phenotype, and that codon 463 was a polymorphic site with no linkage to INH resistance. The Arg463 wild-type MTB isolates predominant in the Western world were replaced by isolates carrying Leu463 in the South China region. RFLP patterns of katG amplicons from respiratory specimens were identical to those of the corresponding MTB cultured colonies. This method has potential application for rapid diagnosis of INH resistance due to katG Ser315Thr mutation.
\end{abstract}

\section{INTRODUCTION}

Tuberculosis remains a global threat to public health. The problem is further complicated by the emergence of multidrug-resistant tuberculosis as a consequence of the widespread use and incautious administration of antibiotics (WHO, 2000). Rapid diagnosis and appropriate chemotherapy become the first priorities in controlling growing epidemics. Nowadays, isoniazid (INH), ethambutol, rifampicin, pyrazinamide and streptomycin are important components of first-line anti-tubercular regimens. INH has a much more complex resistance mechanism than the other four compounds. Several studies have revealed different putative molecular targets of INH, including catalase peroxidase (katG) (van Soolingen et al., 2000), enoyl-acyl

Abbreviations: AFB, acid-fast bacilli; INH, isoniazid; MOTT, Mycobacterium sp. other than tuberculosis; MTB, Mycobacterium tuberculosis. reductase (inhA) (Basso et al., 1998), alkyl-hydroperoxide reductase $(a h p C)$ (Sherman et al., 1996), $\beta$-ketoacyl-acyl carrier protein synthase (kasA) (Mdluli et al., 1998) and NADH dehydrogenase (ndh) (Lee et al., 2001). However, a predominant mutation in the katG locus, Ser315Thr, accounts for more than $50 \%$ of INH-resistance phenotypes, according to earlier reports (Musser et al., 1996; van Soolingen et al., 2000). Mycobacterial strains lacking the entire kat $G$ gene would also exhibit an INH-resistant phenotype (Heym et al., 1995).

In this study, we developed a simple PCR-RFLP method for direct detection of katG Ser315Thr-associated INH-resistant Mycobacterium tuberculosis (MTB) in clinical isolates and respiratory specimens. A total of 906 respiratory specimens and 142 MTB isolates were used to evaluate the specificity and sensitivity of this assay. Results were compared with commercial and in-house PCR assays for MTB, anti-mycobacterial susceptibility testing and DNA sequencing. 


\section{METHODS}

Specimens and isolates. Between December 1999 and February 2002, 906 respiratory specimens (828 expectorated sputum and 78 bronchoalveolar lavage samples) collected from patients suffering from chest symptoms and/or chest radiographic infiltrates of undetermined origin included 675 patients from Queen Mary Hospital and 231 out-patients of Polyclinics of the Department of Health in Hong Kong. An additional 142 clinical isolates of MTB were collected from three major cities in the Pearl River delta of the South China region of China: Hong Kong (96 isolates), Macau (27 isolates) and Guangzhou (19 isolates). Specimens were processed for direct smear followed by concentration for acid-fast bacilli (AFB) culture as described previously (Nolte \& Metchock, 1995). After concentration, digested sediments were divided equally for AFB culture and subsequent PCR assays. Cultures positive for AFB were identified using the AccuProbe hybridization assay (Gen-Probe) and conventional biochemical tests. Catalase test for MTB was performed according to the method of Nolte \& Metchock (1995). Antimicrobial susceptibility testing was performed using the proportional method (NCCLS, 2000).

DNA extraction for PCR. For the digested sediments, the Roche Cobas Amplicor extraction protocol was adopted as described previously (Yam et al., 1998; Yuen et al., 1997). A final volume of $200 \mu \mathrm{l}$ DNA extract was used for subsequent PCRs (undiluted extract). For samples requiring further DNA concentration and purification, $100 \mu \mathrm{l}$ DNA extract was further purified using mini-columns (gel extraction kit; Qiagen) according to the manufacturer's instructions and $30 \mu \mathrm{l}$ purified DNA was eluted $(3 \times$ concentrated extract). For purified culture of MTB on Lowenstein-Jensen medium, a uniform bacterial suspension (McFarland standard no. 1) was made in $0 \cdot 1 \mathrm{M}$ Tris/ $\mathrm{HCl}, \mathrm{pH} 7 \cdot 5$. For the MTB standard strain Rv37, the bacterial suspension was further diluted from $10^{-3}$ to $10^{-10}$ for colony counting using Middlebrook agar plates. All bacterial suspensions were subsequently heated at $100{ }^{\circ} \mathrm{C}$ for $30 \mathrm{~min}$, frozen at $-80^{\circ} \mathrm{C}$, thawed at $80^{\circ} \mathrm{C}$ and centrifuged at $15000 \mathrm{~g}$ for $10 \mathrm{~min}$; the supernatant was used directly for subsequent PCR assays. For the MTB standard strain Rv37, serial dilutions of heated extract were used for determination of analytical sensitivity of the IS6110 and katG PCR assays.

PCR assays for MTB 16S rRNA and IS6110. The Cobas Amplicor MTB test (Roche) uses genus Mycobacterium-specific biotinylated primers to amplify a sequence of $584 \mathrm{bp}$ within a 1500-bp region encoding the $16 \mathrm{~S}$ rRNA of MTB (Yuen et al., 1997). An internal control was incorporated in each reaction to monitor PCR inhibitors. A manual one-tube nested PCR for IS6110 was performed as described previously (Chan et al., 1996; Yam et al., 1998; Yuen et al., 1997).

PCR-RFLP for $\boldsymbol{k}$ atG. Each PCR contained $10 \mu \mathrm{l}$ DNA extract. Primers katG904 (5'-AGCTCGTATGGCACCGGAAC-3', forward primer, positions 904-923) and katG1523 (5'-TTGACCTCCCACCCGACTTG3', reverse primer, positions 1523-1502) (Uhl et al., 1996) were used to amplify a 620-bp fragment of katG. Each $100 \mu \mathrm{l}$ reaction contained 10 $\mathrm{mM}$ Tris/ $\mathrm{HCl}$ (pH 8.3), $50 \mathrm{mM} \mathrm{KCl,} 2 \mathrm{mM} \mathrm{MgCl}_{2}, 0 \cdot 15 \mathrm{mM}$ dNTPs, $0 \cdot 2$ $\mu \mathrm{M}$ each primer and $2 \mathrm{U}$ AmpliTaq Gold polymerase (Perkin Elmer). To activate the Taq polymerase, the mixture was first incubated at $94{ }^{\circ} \mathrm{C}$ for $12 \mathrm{~min}$. Subsequent temperature cycling for 45 cycles started at $94{ }^{\circ} \mathrm{C}$ for $1 \mathrm{~min}, 60^{\circ} \mathrm{C}$ for $1 \mathrm{~min}$ and $72{ }^{\circ} \mathrm{C}$ for $1 \mathrm{~min}$. A $10 \mu \mathrm{l}$ aliquot of the PCR product was electrophoresed for $1 \mathrm{~h}$ through $2 \%$ agarose gel in $1 \times \mathrm{TBE}$. For samples positive for the 620-bp fragment of kat $\mathrm{G}$, a $5 \mu \mathrm{l}$ aliquot of the PCR product was digested using $2 \mathrm{U}$ MspI restriction endonuclease (Amersham Pharmacia Biotech) in a $10 \mu \mathrm{l}$ reaction at $37^{\circ} \mathrm{C}$ for $4 \mathrm{~h}$, followed by electrophoresis in a $6 \%$ polyacrylamide gel. In this study, the INH-resistance mutation in kat G codon 315 (Ser, AGC $\rightarrow$ Thr, ACC) and polymorphic variation in codon 463 (Arg, CGG or Leu, CTG) were identified by RFLP using MspI digestion (restriction site C个CGG).
DNA sequencing of $\mathbf{6 2 0 - b p}$ katG amplicons. To verify the point mutations detected by PCR-RFLP, 620-bp katG amplicons of 20 randomly selected MTB isolates (10 INH-susceptible and $10 \mathrm{INH}$ resistant) were sequenced using BigDye technology and an ABI 377 Genetic Analyzer (Applied Biosystems).

\section{RESULTS AND DISCUSSION}

Among 906 respiratory specimens shown in Table 1, 233 were culture-positive for MTB and 35 were culture-positive for 'Mycobacterium sp. other than tuberculosis' (MOTT), while the remaining 638 were culture-negative for Mycobacterium. Of 187 samples that were AFB smear-positive and culture-positive for MTB, $161(86 \%)$ were positive for $k a t G$ PCR, whereas IS6110 PCR and Roche PCR provided $100 \%$ sensitivity for direct detection of MTB in these specimens. This result is concordant with an experiment on analytical sensitivity that showed that IS6110 PCR was 10 times more sensitive than the kat $G$ PCR (Fig. 1). End-point detection of MTB for IS6110 PCR and katG PCR was found to be 1.5 and 15 c.f.u., respectively. Using a simple column-elution concentrator, all 187 AFB smear-positive specimens and 11/46 (24\%) AFB smear-negative specimens were positive for $k a t G$ PCR. A total of 233 specimens were subsequently confirmed to be culture-positive for MTB, all of which were found to be catalase-positive. A specificity of $100 \%$ was exhibited for the three PCR assays on 906 respiratory specimens with diagnostic sensitivity of $92 \%$ for IS6110 PCR, $86 \%$ for Roche PCR and $85 \%$ for kat $G$ PCR. The kat $G$ PCR is highly specific for MTB, in that none of the specimens with MOTT or those that were culture-positive for other respiratory bacterial pathogens showed a positive result. By Roche PCR, 4.8\% specimens overall were detected to contain PCR inhibitors (data not shown).

The kat $G$ amplicons were further analysed by RFLP using MspI digestion (Table 2) and four distinct RFLP patterns were generated (Fig. 2). All RFLP patterns of kat $G$ amplicons from the 198 respiratory specimens were identical to those of the corresponding MTB isolates, indicating that katG PCR provides reliable detection in clinical specimens. Four catalase-negative MTB isolates were kat $G$ PCR-negative and confirmed INH-resistant by susceptibility testing. These isolates confer INH resistance by partial or complete deletion of kat $G$, accounting for the negative kat $G$ PCR result (Heym et al., 1995). Among the 375 MTB isolates (233 isolates from respiratory specimens and 142 isolates from purified culture), the proportional method identified $273 \mathrm{INH}$-susceptible and $102 \mathrm{INH}-$ resistant MTB isolates. Of the $102 \mathrm{INH}-$ resistant isolates (Hong Kong, 71 isolates; Macau, 19; Guangzhou, 12), $52(51 \%)$ isolates exhibited phenotype Thr315 (RFLP patterns C and D). The remaining 50 (49\%) resistant isolates showed phenotype Ser315 (RFLP patterns A and B). There was no documentation of an outbreak during the study period, and all RFLP patterns were distributed randomly among isolates from the three cities (data not shown). Thr315 is $100 \%$ specific for INH resistance, since no susceptible isolates exhibited Thr315. Automated DNA sequencing of the 620-bp kat $G$ amplicons from 10 randomly 
Table 1. Comparative sensitivities and specificities of three PCR assays for detection of MTB

IS6110 PCR and Roche PCR were performed with undiluted extract. Values are number positive/total (\% positive).

\begin{tabular}{|lcccc|}
\hline Isolates & IS6110 PCR & Roche PCR & \multicolumn{2}{c|}{ katG PCR } \\
\cline { 3 - 5 } & & & $\begin{array}{c}\text { Undiluted } \\
\text { extract }\end{array}$ & $\begin{array}{c}3 \times \text { concentrated } \\
\text { extract }\end{array}$ \\
\hline Respiratory specimens $(n=906)$ & & & & \\
MTB culture-positive: $(n=233)$ & & & & \\
$\quad$ Smear-positive $(n=187)$ & $187 / 187(100)$ & $187 / 187(100)$ & $161 / 187(86 \cdot 1)$ & $187 / 187(100)$ \\
$\quad$ Smear-negative $(n=46)$ & $27 / 46(58 \cdot 7)$ & $13 / 46(28 \cdot 3)$ & $9 / 46(15 \cdot 6)$ & $11 / 46(23 \cdot 9)$ \\
MOTT culture-positive $(n=35)^{*}$ & $0 / 35(0)$ & $0 / 35(0)$ & $0 / 35(0)$ & $0 / 35(0)$ \\
Culture-negative for Mycobacterium & $0 / 638(0)$ & $0 / 638(0)$ & $0 / 638(0)$ & $0 / 638(0)$ \\
$\quad(n=638) \dagger$ & & & & \\
Purified MTB isolates $(n=142)$ & - & - & $138 / 138(100)$ & - \\
Catalase-positive MTB $(n=138)$ & - & - & $0 / 4(0)$ & - \\
Catalase-negative MTB $(n=4)$ & & & & \\
\hline
\end{tabular}

${ }^{\star}$ Nineteen Mycobacterium avium-Mycobacterium intracellulare complex isolates, eight Mycobacterium chelonei, four Mycobacterium gordonae, two Mycobacterium scrofulaceum and two Mycobacterium fortuitum isolates.

$\dagger$ Including 28 isolates of Streptococcus pneumoniae, 13 isolates of Haemophilus influenzae and two isolates of Pseudomonas aeruginosa.

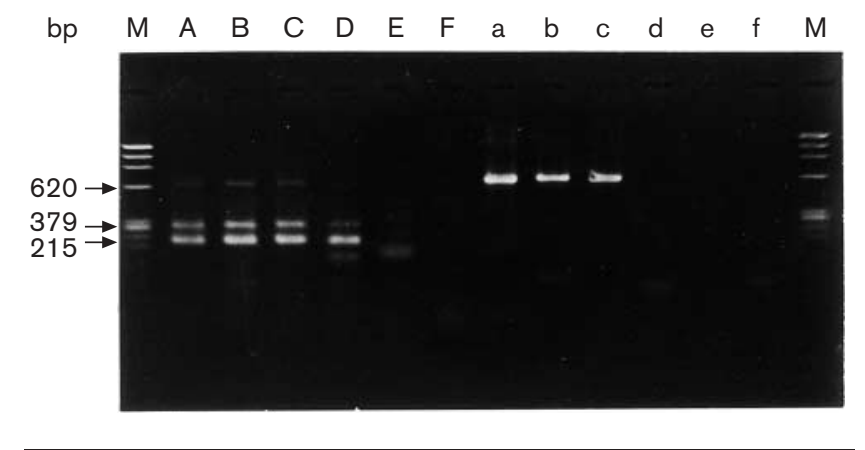

Fig. 1. Analytical sensitivity of IS6110 PCR (lanes A-F) and katG PCR $(a-f)$ with serial dilutions of MTB Rv37 extracts. Lanes: $A, a$, $10^{-5} ; \mathrm{B}, \mathrm{b}, 10^{-6} ; \mathrm{C}, \mathrm{c}, 10^{-7} ; \mathrm{D}, \mathrm{d}, 10^{-8}$; E, e, 10-9; F, f, 10-10; M, molecular size marker $\phi \times 174$. selected INH-susceptible isolates (four isolates of RFLP pattern A and six isolates of RFLP pattern B) and $10 \mathrm{INH}-$ resistant isolates (two, one, three and four isolates, respectively, of RFLP patterns A-D) verified $100 \%$ sequence accuracy of the point mutations detected by PCR-RFLP. DNA sequencing also revealed no mutation other than Ser/ Thr315 and Arg/Leu463 within the 620-bp kat G amplicons for the 20 isolates. Arg463 and Leu463 were identified in $20 \%$ $(20 / 102)$ and $80 \%(82 / 102)$, respectively, of the resistant isolates. Codon 463 is a polymorphic site that does not contribute to INH resistance (van Doorn et al., 2001). In this study, Leu463 was the predominant wild-type MTB isolate in the South China region, replacing the major Arg463 wildtype found in the Western world (Cockerill et al., 1995).

Previous findings showed rapid detection of INH resistance

Table 2. PCR-RFLP patterns of 620 -bp katG fragments for 375 MTB isolates after Mspl digestion

DNA fragments smaller than $30 \mathrm{bp}$ are not shown.

\begin{tabular}{|c|c|c|c|c|c|c|c|c|c|}
\hline \multirow[t]{2}{*}{ Pattern } & \multicolumn{6}{|c|}{ MspI RFLP DNA fragment (bp) } & \multirow[t]{2}{*}{ Amino acids } & \multicolumn{2}{|c|}{ Phenotype } \\
\hline & 228 & 202 & 153 & 137 & 132 & 65 & & $\begin{array}{c}\text { INH-susceptible } \\
\quad(n=273)\end{array}$ & $\begin{array}{l}\text { INH-resistant } \\
\quad(n=102)\end{array}$ \\
\hline A & + & & + & + & & + & Ser315+Arg463 & $38(13.9 \%)$ & $7(6 \cdot 9 \%)$ \\
\hline B & + & + & + & & & & Ser315+Leu 463 & $235(86 \cdot 1 \%)$ & $43(42 \cdot 2 \%)$ \\
\hline $\mathrm{C}$ & + & & & + & + & + & Thr315+Arg463 & $0(0 \%)$ & $13(12 \cdot 7 \%)$ \\
\hline $\mathrm{D}$ & + & + & & & + & & Thr315+Leu463 & $0(0 \%)$ & $39(38.2 \%)$ \\
\hline
\end{tabular}




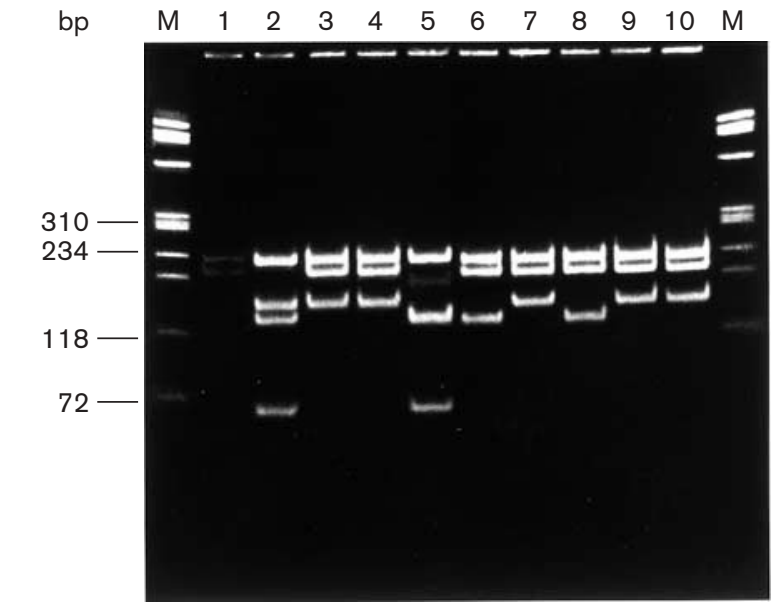

Fig. 2. RFLP patterns of $k a t G$ amplicons after Mspl digestion. Lanes: 1,3, 4, 7, 9 and 10 , pattern $B ; 2$, pattern $A ; 5$, pattern $C ; 6$ and 8, pattern $D ; M$, molecular size marker $\phi \times 174$. Details of RFLP patterns are given in Table 2.

in purified MTB colonies using a real-time PCR assay (Garcia de Viedma et al., 2002) or allele-specific PCR assay (Mokrousov et al., 2002): this is the first report of direct detection of INH resistance-associated mutations of MTB in clinical specimens with highly specific results. Our protocol requires a simple laboratory set-up suitable for a diagnostic microbiology service and the turnaround time can be shortened from $8-10$ weeks to 3 days. In routine practice, respiratory specimens positive for IS6110 or Roche PCR should be subjected to subsequent katG PCR. For katG PCR-positive samples, RFLP should be applied to identify the Ser315Thr substitution. For katG PCR-negative samples, routine mycobacterial culture should be monitored regularly so that MTB colonies identified can be used directly for katG PCRRFLP. The proposed diagnostic algorithm would possibly shorten the turnaround time for identification of INHresistant MTB associated with katG Ser315Thr substitution. However, this PCR-RFLP method only detected $51 \%$ of all INH-resistant MTB in this study. The remaining resistant isolates possibly acquired the INH-resistant phenotype by accumulation of novel mutations in kat $G$ or known mutations of other gene loci, such as inhA or ahpC (Basso et al., 1998; Lee et al., 2001; Mdluli et al., 1998; Sherman et al., 1996). Further understanding of INH-resistance mechanisms in MTB will facilitate the development of PCR-based protocols for rapid diagnosis of the pathogen in clinical specimens.

\section{ACKNOWLEDGEMENTS}

This work was done in partial fulfilment of the requirements of the MPhil degree of the University of Hong Kong by E. T.-Y. L. We thank Dr P. K. Ip, Director of Public Health Laboratory, Macau, and Dr Y. K. Tam, Director of Medical Laboratory, Chest and Lung Hospital, Guangzhou, for the provision of Mycobacterium tuberculosis isolates from patients suffering from pulmonary tuberculosis.

\section{REFERENCES}

Basso, L. A., Zheng, R., Musser, J. M., Jacobs, W. R., Jr \& Blanchard, J. S. (1998). Mechanisms of isoniazid resistance in Mycobacterium tuberculosis: enzymatic characterization of enoyl reductase mutants identified in isoniazid-resistant clinical isolates. J Infect Dis 178, 769-775.

Chan, C. M., Yuen, K. Y., Chan, K. S., Yam, W. C., Yim, K. H., Ng, W. F. \& $\mathrm{Ng}, \mathrm{M}$. H. (1996). Single-tube nested PCR in the diagnosis of tuberculosis. J Clin Pathol 49, 290-294.

Cockerill, F. R., III, Uhl, J. R., Temesgen, Z., Zhang, Y., Stockman, L., Roberts, G. D., Williams, D. L. \& Kline, B. C. (1995). Rapid identification of a point mutation of the Mycobacterium tuberculosis catalaseperoxidase $(k a t G)$ gene associated with isoniazid resistance. J Infect Dis 171, 240-245.

Garcia de Viedma, D., del Sol Diaz Infantes, M., Lasala, F., Chaves, F., Alcala, L. \& Bouza, E. (2002). New real-time PCR able to detect in a single tube multiple rifampin resistance mutations and high-level isoniazid resistance mutations in Mycobacterium tuberculosis. J Clin Microbiol 40, 988-995.

Heym, B., Alzari, P. M., Honore, N. \& Cole, S. T. (1995). Missense mutations in the catalase-peroxidase gene, $k a t G$, are associated with isoniazid resistance in Mycobacterium tuberculosis. Mol Microbiol 15, 235-245.

Lee, A. S. G., Teo, A. S. M. \& Wong, S. Y. (2001). Novel mutations in $n d h$ in isoniazid-resistant Mycobacterium tuberculosis isolates. Antimicrob Agents Chemother 45, 2157-2159.

Mdluli, K., Slayden, R. A., Zhu, Y., Ranaswamy, S., Pan, X., Mead, D., Crane, D. D., Musser, J. M. \& Barry, C. E., III (1998). Inhibition of a Mycobacterium tuberculosis $\beta$-ketocyl ACP synthase by isoniazid. Science 280, 1607-1610.

Mokrousov, I., Otten, T., Filipenka, M., Vyazovaya, A., Chrapov, E., Limeschenko, E., Steklova, L., Vyshnevskiy, B. \& Narvskaya, O. (2002). Detection of isoniazid-resistant Mycobacterium tuberculosis strains by a multiplex allele-specific PCR assay targeting kat $G$ codon 315 variation. J Clin Microbiol 40, 2509-2512.

Musser, J. M., Kapur, V., Williams, D. L., Kreiswirth, B. N., van Soolingen, D. \& van Embden, J. D. (1996). Characterization of the catalase-peroxidase gene (katG) and inhA locus in isoniazid-resistant and -susceptible strains of Mycobacterium tuberculosis by automated DNA sequencing: restricted array of mutations associated with drug resistance. J Infect Dis 173, 196-202.

NCCLS (2000). Susceptibility Testing of Mycobacteria, Nocardia and other Aerobic Actinomycetes. Tentative Standard MT24-T2, vol. 20, 26. Villanova, PA: National Committee for Clinical Laboratory Standards.

Nolte, F. S. \& Metchock, B. (1995). Mycobacterium. In Manual of Clinical Microbiology, 6th edn, pp. 400-437. Edited by P. R. Murray, E. J. Baron, M. A. Pfaller, F. C. Tenover \& R. H. Yolken. Washington, DC: American Society for Microbiology.

Sherman, D. R., Mdluli, K., Hickey, M. J., Arain, T. M., Morris, S. L., Barry, C. E., III \& Stover, C. K. (1996). Compensatory ahpC gene expression in isoniazid-resistant Mycobacterium tuberculosis. Science 272, 1641-1643.

Uhl, J. R., Sandhu, G. S., Kline, B. C. \& Cockerill, F. R., III (1996). PCRRFLP. Point mutations in catalase-peroxidase gene (KatG) of $\mathrm{Myco}$ bacterium tuberculosis associated with isoniazid resistance. In PCR Protocols for Emerging Infectious Diseases, pp. 144-149. Edited by D. H. Persing. Washington, DC: American Society for Microbiology.

van Doorn, H. R., Kuijper, E. J., van der Ende, A., Welten, A. G., van Soolingen, D., de Haas, P. E. \& Dankert, J. (2001). The susceptibility of Mycobacterium tuberculosis to isoniazid and the Arg $\rightarrow$ Leu mutation at codon 463 of kat G are not associated. J Clin Microbiol 39, 1591-1594.

van Soolingen, D., de Haas, P. E. W., van Doorn, H. R., Kuijper, E., Rinder, H. \& Borgdorff, M. W. (2000). Mutations at amino acid position 
315 of the $k a t G$ gene are associated with high-level resistance to isoniazid, other drug resistance, and successful transmission of $\mathrm{Myco-}$ bacterium tuberculosis in the Netherlands. J Infect Dis 182, 1788-1790.

WHO (2000). Anti-tuberculosis Drug Resistance in the World, report no. 2, Prevalence and Trends. WHO/IUATLD Global Project on Antituberculosis Drug Resistance Surveillance. Geneva: World Health Organization.

Yam, W. C., Yuen, K. Y. \& Seto, W. H. (1998). Direct detection of
Mycobacterium tuberculosis in respiratory specimens using an automated DNA amplification assay and a single tube nested polymerase chain reaction (PCR). Clin Chem Lab Med 36, 597-599.

Yuen, K. Y., Yam, W. C., Wong, L. P. \& Seto, W. H. (1997). Comparison of two automated DNA amplification systems with a manual one-tube nested PCR assay for diagnosis of pulmonary tuberculosis. J Clin Microbiol 35, 1385-1389. 